\title{
Cosis and Benefits of Clean Air
}

THE Organisation. for Economic Cooperation and Development specializes in producing reports, but the organization's latest document, which sets out to assess the effects of an increased demand for energy on the environment, is out of the ordinary in that it is both lucid and a mine of useful information on sources of energy (Report and Conclusions of the Joint ad hoc Group on Air Pollution from Fuel Combustion in Stationary Sources, OECD, Paris, 1973). This, however, makes the report no different from several others which have appeared recently in what might be called energy concern year. But the intriguing aspect of the OECD document is a calculation of the likely costs needed to keep the level of gaseous pollutants from these sources at the same level in 1980 as it was in 1968, the base year for the OECD calculations. Between 1968 and 1980, according to all estimates, there will be a two thirds increase in total fuel consumption in most of Europe and in North America, while Japan during this period will increase its consumption by almost $230 \%$. And if no action is taken to abate the gaseous pollutants from power stations and other industrial sources the level of these pollutants will increase by $70 \%$ by the end of the decade.

During the next ten years the price of all fuels, except possibly uranium and plutonium for nuclear power generation, will inexorably rise. And equally inexorably there are going to be pressures applied, quite properly, to keep the exhaust fumes from power stations and industry as clean and free of sulphur dioxide and nitrogen oxides as possible. But what increase in fuel costs should be tolerated in order to maintain the environment in its present state? There is no point in pretending that the consumer will not pay the increase in the end, for in spite of the often enunciated principle that the polluter must pay, the cost will appear on the electricity or gas bill, on the price of the product, or in some cases as an increase in taxes. But the news from the OECD is cheerful enough this time. Only an estimated $2.5 \%$ to $5 \%$ increase in fuel costs is necessary to keep sulphur dioxide emissions constant for the next few years. Such an increase is, of course, much less than the expected increase in fuel prices in the same period, and for once, the benefits of this increase in cost would seem to clearly outweigh the disadvantages.

But sulphur dioxide emissions do not constitute the entire story. Nitrous oxides and dust are also emitted from industrial stacks and the report does not consider the pollutants emitted from internal combustion engines. Unfortunately, the way in which nitrous oxides, which are one of the chief pollutants in car exhausts, contribute to chemical reactions in the atmosphere is not completely understood. And because of this the best way to treat these gases before they are emitted to the atmosphere is a contentious topic. But the technology is now available, at a cost, to reduce the amount of these oxides emitted even if little is known about how the oxides cause problems. Although the cost of keeping sulphur dioxide emissions at a low level is modest when expressed in terms of the total spent on fuels it still means a capital investment of anything up to $\$ 15,600$ million, a not insubstantial sum, in the next few years and the annual extra operating costs would run to between $\$ 2,200$ million and $\$ 4,200$ million. But the OECD report raises the question of whether individual countries should decide to try and return the pollutant levels to those existing in 1968, or whether this should be an international approach. The OECD points out that it is feasible to control the amounts of sulphur dioxide emitted but the wider aspect is whether it is sensible to attack one part of the problem of air pollution while ignoring other substances which are being continually emitted into the environment. Certainly sulphur dioxide emissions should be contained within reasonable limits, but it is surely not fair that industries which burn fuels with a high sulphur content should be made to wear environmental halos while other industries which pollute in a different way should have no strictures put upon them. What is surely needed is an overall policy, similar to that for which the European Economic Commission has pleaded, which does not favour one side of industry over another.

\section{Years Ago}

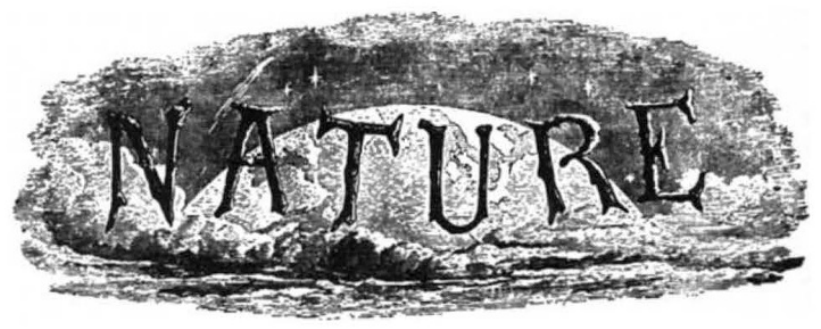

Telescope Tube for Celestial Photography I HAVE not yet seen any satisfactory plan suggested of getting over the difficulty experienced in celestial photography by the expansion and contraction of telescope tubes, by changes of temperature in metal tubes.

I therefore venture to suggest the following plan, which may be so arranged as to keep the object-glass and camera-slide exactly the same distance apart, and so keep the true focus when once found. The arrangement would have to be modified ac. cording to the metal of which the tube is made, but taking a brass one (the most common), with the camera attached to the eyepiece-slide, the correction will be effected by attaching to the main tube, near the eyepiece, two zinc rods the length of the main tube, upon which they must rest loosely ; to the free ends of these, near the object-glass, attach a rod of iron extending to the eye-tubc; let this iron rod be attached to the eye-tube when the sensitive-plate is exactly in focus; any change in temperature will then have no effect on the focus, for the expansion and contraction of the three metals will keep the distance from object-glass to sensitive-plate constant. All who have worked with a telescope giving sharp definition, will know that this is not an unnecessary precaution, as it may seem to some.

Sydney Observatory, June 14

H. C. RUSSELI

From Nature 8, 284, August 7, 1873. 